\title{
Pertumbuhan Fusarium Verticillioides, Aspergillus flavus, dan Eurotium chevalieri pada Berbagai Media
}

Gergonius Fallo ${ }^{\mathrm{a}}$

${ }^{a}$ Fakultas Ilmu Pendidikan, Universitas Timor, Kefamenanu, TTU - NTT, Indonesia.

\section{Article Info}

Article history:

Received 5 Mei 2017

Received in revised form 17 Juni 2017

Accepted 5 Juli 2017

\section{Keywords:}

Fusarium Verticillioides

Aspergillus flavus

Eurotium chevalier

\begin{abstract}
Abstrak
Fusarium verticillioides, Aspergillus flavus, dan Eurotium chevalieri merupakan cendawan perusak bahan pangan yang ditemukan pada saat bahan pangan belum dipanen atau setelah bahan pangan dipanen. Pertumbuhan ketiga cendawan ini sangat dipengaruhi oleh nutrisi yang terkandung pada media tumbuh. Penelitian ini bertujuan untuk membandingkan pertumbuhan Fusarium verticillioides, Aspergillus flavus, dan Eurotium chevalieri pada beberapa media untuk isolasi dan identifikasi. Ketiga cendawan tersebut ditumbuhkan pada media yang berbeda yaitu Chloramphenicol Peptone Agar (DCPA), Dichloran 18\% Glycerol Agar (DG18), Czapek Yeast Extract Agar (CYA), Czapek Yeast Extract Agar 20\% Sucrose (CY20S), Malt Extract Agar (MEA), dan 25\% Glycerol Nitrate Agar (G25N) dan diinkubasi pada suhu $\pm 28^{\circ} \mathrm{C}$. Pengamatan koloni dilakukan setiap $2 \times 24$ jam, 4 × 24 jam, dan 6 × 24 jam selanjutnya diameter isolat diukur. Hasil isolasi pertumbuhan dan panjang diameter koloni dari A. Flavus $(61 \mathrm{~mm})$ dan E. Chevalieri $(45 \mathrm{~mm})$ diketahui dapat tumbuh baik pada media DG18, sedangkan $F$. verticillioides $(46 \mathrm{~mm})$ tumbuh baik di media DCPA. Sementara pada media identifikasi A. Flavus $(80 \mathrm{~mm})$ dapat tumbuh baik pada media CY20S, sedangkan E. Chevalieri $(40 \mathrm{~mm})$ dapat tumbuh baik pada media G25N dan CY20S. Koloni $F$. verticillioides $(62 \mathrm{~mm})$ dapat tumbuh baik di media CYA dan CY20S. (2017 dipublikasikan oleh Savana Cendana.
\end{abstract}

\section{Pendahuluan}

Di negara beriklim tropis seperti Indonesia, bahan pangan dapat terserang oleh serangga, tungau, tikus dan mikroba. Cendawan merupakan mikroba utama yang menyerang biji-bijian baik sebelum panen atau cendawan lapangan maupun setelah panen atau cendawan pascapanen. Cendawan membutuhkan nutrisi sebagai sumber energi dan kondisi lingkungan tertentu untuk proses pertumbuhan dan reproduksi. Nutrien dan kondisi yang optimum merupakan syarat yang harus dipenuhi untuk membangun komponen-komponen seluler baru dan menghasilkan energi yang dibutuhkan dalam proses kehidupan sel.

Secara alami mikroba akan beradaptasi pada lingkungan yang paling sesuai untuk kebutuhan cendawan tersebut. Smith (1994) melaporkan cendawan memiliki variasi lingkungan yang luas dengan menggunakan substrat baik substrat alami maupun buatan. Beberapa spesies cendawan diantaranya belum diketahui nutrisi yang tepat untuk pertumbuhannya, sehingga masih tidak dapat ditumbuhkan pada media buatan.

Menurut susunannya, medium dapat dibagi menjadi tiga golongan yaitu medium alami, medium semi sintetik dan medium sintetik. Susunan media mencerminkan kebutuhan dasar cendawan untuk tumbuh dan berkembangbiak sehingga media harus mengandung air, sumber karbon atau energi, unsur hara dan faktor tumbuh. Berbeda sampel maka berbeda media untuk mengidentifikasi cendawan. Berdasarkan laporan Alborch et al. (2010) media selektif Nash and Snyder medium (NS) dan malachite green agar 2.5 (MGA 2.5) adalah media yang digunakan untuk mendeteksi adanya infeksi Fusarium sp. pada jagung lokal dan jagung transgenik.

Menurut Park \& Bullermann (1983) substrat merupakan salah satu faktor yang paling penting mengendalikan produksi metabolit sekunder. Selain itu, media yang optimal untuk produksi metabolit sekunder oleh cendawan bergantung pada proses metabolisme, spesies, dan isolasinya (Medina 2006). Sebagai contoh, strain yang berbeda dari A. flavus telah terbukti untuk menghasilkan aflatoksin pada tingkat yang berbeda ketika dikultur pada kondisi yang sama (Hussein 2001). Beberapa media khusus yang dikembangkan dapat mengidentifikasi strain toksigenik Aspergillus, seperti Aspergillus flavus dan Parasiticus agar (AFPA) (Pitt et al. 1983).

Isolasi cendawan di laboratorium membutuhkan media yang tepat, kebutuhan akan lingkungan hidup yang sesuai untuk cendawan harus dapat dipenuhi oleh media yang merupakan representasi dari kondisi habitat cendawan tersebut. Cendawan dapat dibiakkan pada berbagai jenis substrat namun respon tumbuh yang dihasilkan dapat berbeda untuk tiap spesies cendawan karena keperluan nutrisi yang berbeda. Beberapa cendawan dapat tumbuh dengan baik pada medium yang mengandung beberapa bahan organik, sedang cendawan yang lain memerlukan zat-zat kimia tertentu. Spesies cendawan lapangan misalnya Fusarium verticillioides dan cendawan pascapanen misalnya Aspergillus flavus ada yang tumbuh baik dengan media dengan kadar gula atau kadar garam yang rendah maupun tinggi, sedangkan Eurotium chevalieri dapat hidup pada kadar gula atau garam yang tinggi, pada penelitian ini akan diamati pertumbuhan cendawan terhadap berbagai media.

\section{Metode}

Penelitian ini dilaksanakan di Laboratorium Semea Biotrop Bogor bulan Juli 2014 hingga September 2014. Biakan induk F. verticillioides pada PDA, A. flavus pada APFA, E. chevalieri pada CY20S yang telah diinkubasi dipindahkan pada media DCPA, DG18, CYA,CY20S, umur inokulum dibuat seragam. Biakan induk dipotong menggunakan cork borer berdiameter $4 \mathrm{~mm}$ yang inokulumnya berasal dari tepi koloni, dengan memakai jarum ose potongan isolat tersebut ditanam secara aseptik tepat ditengah-tengah cawan Petri yang berisi media DCPA, DG18, CYA, CY20S kemudian diinkubasi pada suhu ruang $\pm 28^{\circ} \mathrm{C}$. Pengamatan koloni dilakukan setiap $2 \times 24,4 \times 24$, dan $6 \times$ 24 jam selanjutnya diameter isolat diukur. Pengukuran dilakukan dengan membuat dua garis penampang melintang pada cawan petri yang melewati bagian tengah perpotongan koloni ditandai dengan kedua garis tersebut.

\section{Hasil dan Pembahasan}

Media untuk isolasi cendawan lapangan dan cendawan pascapanen pada berbagai bahan pangan, idealnya adalah media tersebut mendukung pertumbuhan organisme dan membantu dalam identifikasi cendawan. Hasil pengamatan pertumbuhan $F$. verticillioides, A. flavus, dan E. chevalieri pada beberapa media dapat dilihat pada Tabel 1.

Tabel 1. Lama inkubasi, diameter koloni cendawan Aspergillus flavus, Fusarium verticillioides, dan Eurotium chevalieri pada beberapa media tumbuh

\begin{tabular}{ccccc}
\hline \multirow{2}{*}{ Media } & Inkubasi & \multicolumn{3}{c}{ Diameter koloni $(\mathrm{mm})$} \\
\cline { 3 - 5 } & (jam) & A. flavus & F. verticillioides & E. chevalieri \\
\hline DCPA & $2 \times 24$ & 25 & 19 & 12 \\
& $4 \times 24$ & 41 & 35 & 12 \\
DG18 & $6 \times 24$ & 47 & 46 & 12 \\
& $2 \times 24$ & 21 & 15 & 23 \\
& $4 \times 24$ & 44 & 24 & 33 \\
CYA & $6 \times 24$ & 61 & 32 & 45 \\
& $2 \times 24$ & 39 & 23 & 14 \\
CY20S & $4 \times 24$ & 50 & 48 & 17 \\
& $6 \times 24$ & 73 & 62 & 20 \\
& $2 \times 24$ & 33 & 21 & 21 \\
MEA & $4 \times 24$ & 64 & 20 & 30 \\
& $6 \times 24$ & 80 & 53 & 39 \\
& $2 \times 24$ & 29 & 20 & 11 \\
G25N & $4 \times 24$ & 44 & 37 & 11 \\
& $6 \times 24$ & 61 & 46 & 11 \\
& $2 \times 24$ & 13 & 6 & 32 \\
& $4 \times 24$ & 16 & 6 & 40 \\
\hline
\end{tabular}

Hasil pengamatan pertumbuhan cendawan A. flavus dan F. verticillioides dan E. chevalieri pada beberapa media yaitu: Dichloran-Kloramfenikol Pepton Agar (DCPA), Dichloran 18\% Glycerol Agar (DG18), Czapek Yeast Extract Agar (CYA), 25\% Glycerol Nitrate Agar (G25N), Czapek Yeast Extract Agar with $20 \%$ Sucrose (CY20S) dan Malt Extract Agar (MEA) secara keseluruhan dapat tumbuh dengan baik walaupun panjang diameter koloninya bervariasi. Hasil pertumbuhan cendawan A. flavus, F. verticillioides dan E. chevalieri dengan diameter koloni pada beberapa media terlihat pada Gambar 1 .

Media DCPA dan DG18 adalah media umum untuk mengisolasi cendawan pada bahan pangan. Menurut Andrews \& Pitt (1986) media DCPA digunakan untuk menumbuhkan cendawan umum yang terdapat pada biji-bijian. Media DG18 adalah media umum yang digunakan terutama untuk mengisolasi cendawan xerofilik, yaitu cendawan yang tumbuh dan berkembang pada substrat dengan kadar air rendah seperti serealia, kacang-kacangan, tepung dan rempah-rempah. Contoh cendawan xerofilik yaitu Eurotium, Aspergillus restrictus, A. penicillioides, Walemia sebi. Eurotium merupakan tingkat teleomorf Aspergillus. Sebagian besar spesies dari Aspergillus dapat tumbuh dengan baik pada media tersebut (Hocking \& Pitt 1980).

Hasil pengamatan terhadap diameter pertumbuhan koloni setelah inkubasi $6 \times 24$ jam dengan suhu $28^{\circ} \mathrm{C}$, pada media DCPA A. flavus memilik diameter koloni $47 \mathrm{~mm}, F$. verticillioides $46 \mathrm{~mm}$, dan $E$. Chevalier $12 \mathrm{~mm}$ Sedangkan pada media DG18, A. flavus memiliki diameter koloni $61 \mathrm{~mm}, F$. verticillioides $32 \mathrm{~mm}$, dan E. chevalieri $45 \mathrm{~mm}$. Kedua media ini mengandung senyawa dichloran dan choramphenicol untuk menghambat atau mengurangi penyebaran pertumbuhan cendawan yang tumbuhnya cepat. Jika dibandingkan berdasarkan diameter pertumbuhan koloni, media umum DG18 paling ideal bagi pertumbuhan A. flavus, dan E. chevalieri. Sedangkan media DCPA paling ideal untuk pertumbuhan $F$. Verticillioides. 

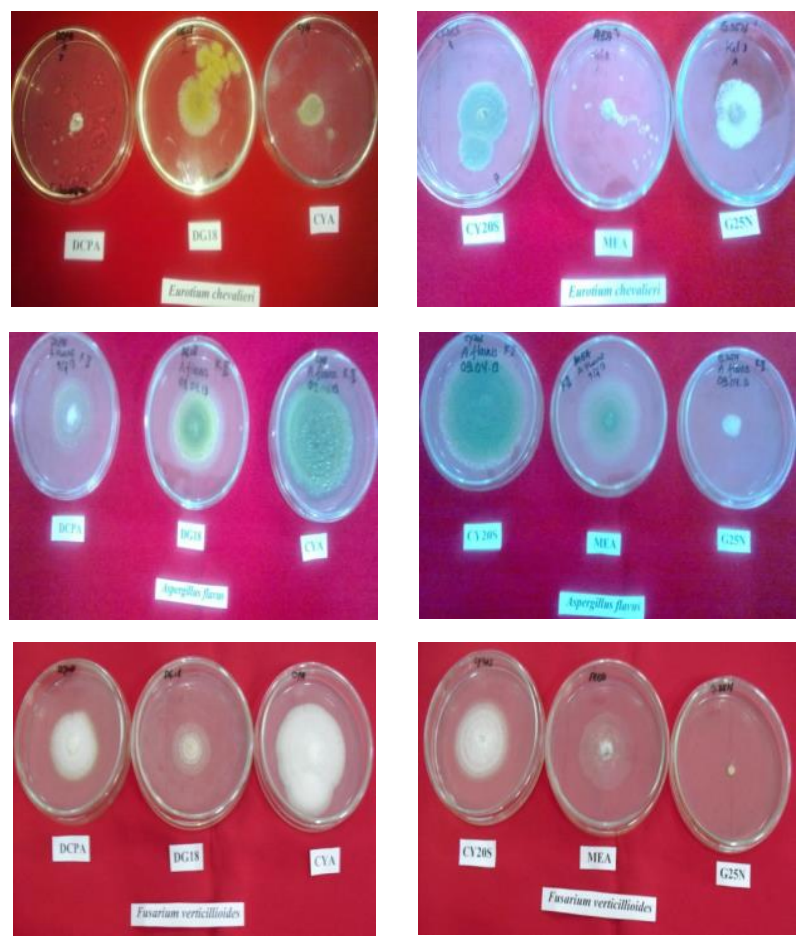

Gambar 1. Hasil isolasi A. flavus, F. Verticillioides, E. chevalieri pada beberapa media.

Hasil penelitian Dharmaputra (1994) untuk mengisolasi kapang pada beras dari beberapa varietas padi menggunakan media DG18. Hasil isolasi diperoleh 14 spesies kapang termasuk spesies kapang pascapanen A. flavus dan E. Chevalieri. Sebuah studi kolaboratif Braendlin (1995) untuk membandingkan media tumbuh DG18 dengan Dichloran Rose Benyal Chloramphenicol Agar (DRBC) dan Malt Extract Yeast 50\% Glucose Agar (MY50G) dengan menggunakan sampel dari ragi termasuk spesies Eurotium spp. Hasil secara keseluruhan menunjukan bahwa ragi xerofilik yang ditumbuhkan pada media DG18 setelah diinkubasi 5 hari pada suhu $25^{\circ} \mathrm{C}$ lebih unggul.

Menurut Pitt \& Hocking (1997), untuk identifikasi cendawan lapangan digunakan media Potato Dxtrose Agar (PDA) dan Czapek Yeast Extract Agar (CYA), sedangkan untuk identifikasi cendawan pascapanen (terutama Aspergillus) digunakan tiga media, yaitu CYA, Malt Extract Agar (MEA) dan 25\% Glycerol Nitrate Agar (G25N). Untuk identifikasi cendawan pascapanen yang xerofilik sepert Eurotium digunakan media Czapek Yeast Extract Agar yang mengandung 20\% sucrose (CY20S).

Berdasarkan hasil pengamatan diameter pertumbuhan koloni cendawan pada media identifikasi CY20S, CYA, G25N dan MEA selama inkubasi 6 x 24 jam pada suhu $28^{\circ} \mathrm{C}$, A. flavus merupakan cendawan pascapanen yang paling cepat tumbuh di media CY20S dan memiliki diameter koloni $80 \mathrm{~mm}$. Sedangkan masing-masing di media CYA $73 \mathrm{~mm}$, MEA $61 \mathrm{~mm}$ dan di media G25N $16 \mathrm{~mm}$. F. verticillioides adalah cendawan lapangan. Hasil pengamatan menunjukan bahwa spesies cendawan ini dapat tumbuh baik pada media CYA dengan memiliki diameter koloni $62 \mathrm{~mm}$, CY20S $53 \mathrm{~mm}$, MEA $46 \mathrm{~mm}$ dan G25N $6 \mathrm{~mm}$. Sedangkan E. chevalieri merupakan cendawan pascapanen dan dapat tumbuh baik pada media identifikasi G25N dengan diameter koloninya $40 \mathrm{~mm}$, CY20S $39 \mathrm{~mm}$, CYA $20 \mathrm{~mm}$ dan MEA $11 \mathrm{~mm}$. Jika dibandingkan, $A$. flavus paling ideal tumbuh di media identifikasi CY20S dan E. chevalieri paling ideal tumbuh di media CY20S dan G25N. Sedangkan F. verticillioides paling ideal untuk identifikasi ditumbuhkan pada media CYA.

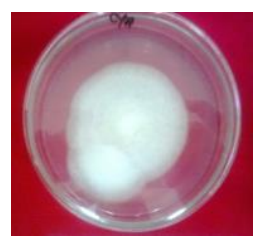

a

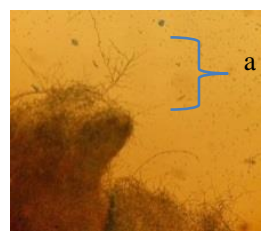

$\mathrm{b}$
Gambar 2. a Isolat murni $F$. verticillioides pada media CYA, b Foto mikrogra morfologi F.verticillioides perbesaran 40x berupa makrokonidia, mikrokonidia, fialid.

Hasil pengamatan morfologi $F$. verticillioides pada media CYA (Gambar 2.), macroconidia umumnya memiliki setidaknya tiga septa, dengan sel apikal yang dapat dibedakan, berbentuk bulat, bengkok atau filamen, dan sel basal yang berbentuk kaki, atau hanya sedikit berlekuk. $F$. verticillioides menghasilkan microconidia yang panjang, halus, rantai kering, yang sebaiknya diamati dengan menggunakan 10x. Beberapa spesies menghasilkan microconidia palsu di kepala (kecil, berlendir, konidia bulat) dan tergantung pada spesies. dalam beberapa spesies, microconidia diproduksi pada phialides dengan hanya satu pori disebut monophialides, namun beberapa spesies menghasilkan phialides dengan lebih dari satu pori (polyphialides). Spesies yang memproduksi polyphialides biasanya menghasilkan monophialides juga (Pitt \& Hocking 1997).

Hasil pengamatan secara makroskopis koloni A. flavus di media CYA secara umum membentuk koloni yang granuler, berserabut dengan beberapa warna koloni, ada yang putih dan kuning (Gambar 3.).

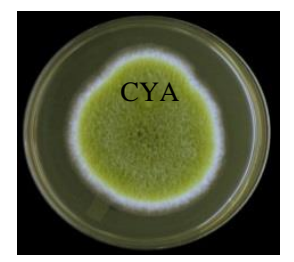

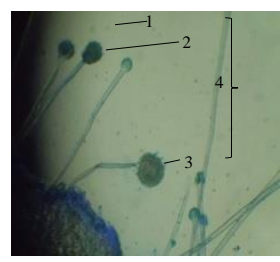

Gambar 3. Hasil pemurnian: a. isolat Aspergillus flavus yang ditumbuhkan pada media CYA, b. Foto mikrograf morfologi Aspergillus flavus perbesaran 40x. 1= konidia; $2=$ vesikula, $3=$ metula, fialid dan konidium, 4= konidiofor

Secara morfologi konidiofor A. flavus memiliki panjang tangkai $400 \mu \mathrm{m}-1$ $\mathrm{mm}$, berdinding kasar; vesikula bulat berdiameter $20-45 \mu \mathrm{m}$, fertil pada tiga perempat permukaannya, membentuk metula dan fialid, tetapi pada beberapa isolat sebagian kepala hanya membentuk fialid, ukuran metula dan fialid sama, panjang 7-10 $\mu \mathrm{m}$; konidium bulat sampai agak bulat, biasanya berdiameter 3.5$5 \mu \mathrm{m}$, dengan dinding yang relatif tipis, agak kasar; sklerotium pada awalnya putih, menjadi keras dan coklat kemerahan sampai hitam, membulat dengan diameter 400-800 $\mu \mathrm{m}$ (Pitt \& Hocking 1997). Hasil pemurnian dan foto mikrograf morfologi Eurotium chevalieri pada media CY20S terlihat pada Gambar 4.

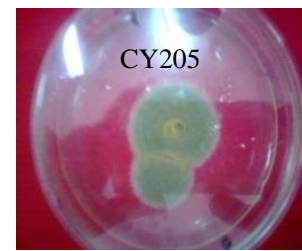

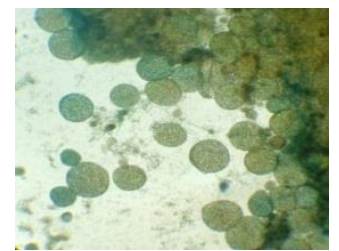

Gambar 4. Hasil pemurnian: a. isolat Eurotium chevalieri yang ditumbuhkan pada media CY20S, b. Foto mikrograf morfologi Eurotium chevalieri perbesaran $40 \mathrm{x}$ berupa kleistotesium yang berisi askus dan di dalam askus terdapat 8 askospora

Miselium Eurotium chevalieri berwarna kuning terang, seringkali lebih gelap di bagian tengahnya, menyelubungi kleistotesium berwarna kuning dan berlimpah, dilapisi oleh kepala konidium yang jarang sampai berlimpah, berwarna hijau keabuan; kleistotesium berwarna kuning terang, bulat, berdiameter 100-140 $\mu \mathrm{m}$, diselubungi oleh hifa vegetatif berwarna kuning hingga oranye; askospora berwarna kuning, bentuk menjorong (ellipsoidal) berbentuk seperti roda kerekan, panjang 4.5-5 $\mu \mathrm{m}$, berdinding halus, dengan dua flens yang menyolok, paralel, sempit, kadang-kadang berliku; konidiofor berasal dari hifa aerial, panjang tangkai $400-700 \mu \mathrm{m}$, berdinding tipis; vesikula berdiameter $25-35 \mu \mathrm{m}$, fertil di seluruh permukaannya, hanya membentuk fialid yang berbentuk seperti ampula, panjang 5-8 $\mu \mathrm{m}$; konidium menjorong atau berbentuk seperti tong anggur (barrel), panjang 4-5.5 $\mu \mathrm{m}$, dengan dinding berstruktur seperti duri kecil (Pitt \& Hocking, 1997).

\section{Simpulan}

Spesies cendawan lapangan dan cendawan pascapanen pada berbagai bahan pangan dapat tumbuh baik pada media isolasi dan identifikasi. Hasil pengamatan pada beberapa media tumbuh setelah inkubasi $6 \times 24$ jam pada suhu ruang $28^{\circ} \mathrm{C}$ dan pengamatan panjang diameter koloni, spesies cendawan pascapanen A. flavus dan E. chevalieri dapat tumbuh baik di media isolasi umum DG18 dengan panjang diameter koloni masing-masing $61 \mathrm{~mm}$ dan 45 mm. Sedangkan spesies cendawan lapangan $F$. verticillioides dapat tumbuh baik di media DCPA dengan panjang diameter koloni $46 \mathrm{~mm}$. Sementara pada media identifikasi CY20S dan CYA, A. flavus dapat tumbuh baik dengan panjang diameter koloni $80 \mathrm{~mm}$ dan $73 \mathrm{~mm}$. Pada media G25N dan CY20S, $E$. chevalieri dapat tumbuh baik dengan panjang diameter koloni $40 \mathrm{~mm}$ dan 39 mm. Sedangkan $F$. verticillioides dapat tumbuh baik di media CYA dan CY20S dengan panjang diameter koloni $62 \mathrm{~mm}$ dan $53 \mathrm{~mm}$.

\section{Pustaka}

Andrews S, Pitt JI. 1986. Selective Media for Fusarium Species and Dematiaceous Hyphomycetes from Cereals. Appl Environ Microbiol. Vol 51. hlm. 1235-1238. 
Alborch L, Bragulat MR, Cabañes FJ. 2010. Comparison of Two Selective Culture Media for The Detection of Fusarium Infection in Conventional and Transgenic Maize Kernels. Lett Appl Microbiol. vol 50, hlm. 270-281.

Braendlin N. 1995. Enumeration of Xerophilik Yeasts in The Presence of Zerophilik Moulds: a Collaborative Study. Fod microbiology. Vol 29. hlm 185-192.

Dharmaputra OS. 1994. Kapang pada Beras yang Berasal dari Beberapa Varietas Padi. Hayati. Vol 1, hlm 37-41

Hocking AD, Pitt JI. 1980. Dichloran-Glycerol Medium for Enumeration of Xerophilic Fungi from Low Moisture Foods. Appl Environ Microbiol vol 39. hlm 488-492.

Medina. 2006. Survey of the Mycobiota of Spanish Malting Barley and Evaluation of the Mycotoxin Producing Potential of Species of Alternaria, Aspergillus and Fusarium. J Food Microbiol. Vol 108, hlm. 196-203.

Park KY, Bullerman IB. 1983. Effect of Cycling Temperatures on Aflatoxin Production by Aspergillus Parasiticus and Aspergillus Flavus in Rice and ar Cheese. Journal Of Food Science. Vol 48, hlm. 889-896.

Smith D, Onions HS. 1994. The Preservation and Maintenance of Living Fungi $2^{\text {ed }}$. London (GB): Commonwealth Agricultural Bereaux International.

Pitt JI, Hocking AD. 1997. Fungi and Food Spoilage. London: Blackie Academic and Professional.

Pitt JI, Hocking A, Glenn DR. 1983. Na Improved Medium for The Detection of Aspergillus flavus and Aspergillus parasiticus. J Appl Bacteriol. Vol 54, hlm. 109-114. 